\title{
RANS Study of Flows across an Abrupt Change in Surface Roughness
}

\author{
W. $\mathrm{Li}^{1}$, C. H. Liu ${ }^{1 \dagger}$ and W. C. Cheng ${ }^{2,3}$ \\ ${ }^{1}$ Department of Mechanical Engineering, The University of Hong Kong, Hong Kong \\ ${ }^{2}$ School of Atmospheric Sciences, Sun Yat-sen University, Guangzhou, PR China \\ ${ }^{3}$ Southern Laboratory of Ocean Science and Engineering, Guangdong, Zhuhai, PR China \\ †Corresponding Author Email: liuchunho@graduate.hku.hk
}

(Received October 1, 2019; accepted March 2, 2020)

\begin{abstract}
Flows across an abrupt change in surface roughness lead to the development of an internal boundary layer (IBL). In this paper, the effect of surface discontinuity on the structure of flow and turbulence is unveiled by the Reynolds-averaged Navier-Stokes (RANS) turbulence model. Three configurations of smooth-to-rough transition, which are fabricated by sinusoidal wavy surfaces, are examined to contrast the flow adjustment. After the change in (increasing) surface roughness, the flows decelerate and the downward momentum flux $\left(-\overline{u " w^{\prime \prime}}\right)$ increases to overcome the increasing drag. The changes in friction velocity $\left(u_{\tau, 2} / u_{\tau, 1}\right)$ and roughness length $\left(z_{0,2} / z_{0,1}\right)$ follow the conventional power law. The developments of roughness sublayer (RSL) and inertial sublayer (ISL), which characterize the flows adjustment, are clearly observed. The flow structure after the roughness transition is also defined quantitatively, through which the interaction among IBL, RSL and ISL is elucidated. The growth of IBL and ISL signifies that the influence from the upstream (smoother) surface is being weakened while the flows are developing in equilibrium with the downstream (rougher) surface. Finally, the winds over complex terrain (Hong Kong Island) are modelled to demonstrate the sea-land effect on atmospheric flows. The results show that the flow dynamics and structure over natural topography are consistent with those over idealised surfaces.
\end{abstract}

Keywords: Atmospheric flows; Computational Fluid Dynamics (CFD); Internal Boundary Layer (IBL); Natural topography; Surface-roughness change; Turbulence characteristics.

\section{NOMENCLATURE}

$\begin{array}{ll}C_{d} & \text { drag coefficient } \\ d & \text { zero-plane displacement height } \\ h & \text { internal boundary layer (IBL) height } \\ L & \text { domain extent } \\ n & \text { exponent } \\ N & \text { number of wave units } \\ \operatorname{Re} & \text { Reynolds number }=U_{\infty} \delta / v \\ \tau_{w} & \text { wall shear stress } \\ u, w & \text { streamwise and vertical wind speeds } \\ U_{\infty} & \text { freestream wind speed } \\ x & \text { streamwise distance after the crest } \\ x, z & \text { streamwise and vertical coordinate } \\ z w & \text { elevation of bottom solid boundary } \\ u_{\tau} & \text { friction velocity } \\ z 0 & \text { roughness length }\end{array}$

\section{INTRODUCTION}

Coastal wind environment has aroused public concern because of the economic implication such as commercial zones (ports and praya), residential areas

$\begin{array}{ll}\delta & \text { turbulent boundary layer height } \\ \Delta K & \text { TKE increase ratio } \\ \Delta P_{x} & \text { background pressure gradient } \\ \Delta S & \text { speed-up ratio } \\ \kappa & \text { von Kármán constant }=0.41 \\ \lambda & \text { wavelength of wavy wall surface } \\ \Lambda & \text { amplitude of wavy wall surface } \\ \nu & \text { kinematic viscosity } \\ \phi & \text { variable } \\ \Phi & \text { dimensionless wind shear } \\ \rho & \text { density Accent } \\ \bar{\phi} & \text { mean property } \\ \text { Subscript } & \\ 1 & \text { upstream property } \\ 2 & \text { downstream property }\end{array}$

(hotels and resorts) and public utilities (power plants and waste treatment). Onshore (or offshore) winds encounter abrupt changes in surface roughness or even topography elevation so the conventional theory of horizontally homogeneous atmospheric 
surface layers (ASLs), which is based on the fully developed flows in equilibrium with the underlying rough surfaces, is no longer applicable. After the surface discontinuity, the outer flows (upper layer) retain the upstream characteristics $\phi_{1}$ while the nearsurface flows (lower layer) $\phi_{2}$ are adjusting to the new (rougher or smoother) downstream boundary conditions (BCs), leading to the growth of an internal boundary layer (IBL) originating at $x_{2}=0$.

The effect of rough surfaces on the dynamics aloft is usually parametrized by the roughness length $z_{0}$ and the zero-plane displacement height $d$ (Garratt 1994) instead of resolving the roughness elements explicitly. The logarithmic wind profile (log-law) for the inertial sublayer (ISL)

$$
\frac{\bar{u}}{u_{\tau}}=\frac{1}{\kappa} \ln \left(\frac{z-d}{z_{0}}\right)
$$

is therefore assumed even in the vicinity over sizeable roughness elements (such as buildings). Its benefit is the systematic control (modelling) of aerodynamic resistance by $z_{0}$ and $d$. However, the log-law, which is devised based on horizontally homogeneous ABLs, is merely valid for the flows over surface discontinuity. Moreover, the dynamics around individual roughness elements initiates the roughness sublayers (RSLs) in which the transport is different from their ISL counterparts (Ho and Liu 2017). The extrapolation of log-law from the ISL down to the roughness-element level induces inaccuracy so does the subsequent IBL development. Studies of the RSL flows were commonly conducted over forest canopy (Dellwik and Jensen 2005) but not urban canopy. This study is therefore conceived, by explicitly resolving the roughness elements, to examine how surface discontinuity affects IBL flows and structure. We unprecedentedly look into the RSLs and the modelling uncertainty of log-law BCs in IBLs. Surface roughness and topographical variation alternate the shear and the wind direction (Schwiesow and Lawrence 1982). Both idealised wavy surfaces and natural topography are tested to seek for a fundamental understanding.

Flows over an abrupt change in surface roughness is a classic problem. Analytical solution to the Kármán's integral together with the log-law was used to diagnose the dynamics downstream a surface discontinuity more than half century before (Elliott 1958 and Townsend 1966). Assuming two independent log-laws in the IBLs, the upper layer leads to discontinuous flows and/or shear stress at the interface. Introducing a continuous variation between the two log-laws eases the problem but elevates the IBL top (Panofsky and Townsend 1964). Nevertheless, it has been shown that the IBL height $h$ grows as the $4 / 5$ power of the downwind distance $x_{2}$

$$
h / z_{0,2} \propto\left(x_{2} / z_{0,2}\right)^{4 / 5}
$$

for both smooth-to-rough and rough-to-smooth transitions. Moreover, the transport after the discontinuity is augmented (Peterson 1971) and the empirical relation between friction velocity and roughness length (Taylor 1962) is

$$
u_{\tau, 2} \propto z_{0,2}^{n}
$$

where the exponent is in the range of $0.1 \leq n \leq 0.16$ obtained from wind tunnel experiments. However, the analytical solution Eq. (2) assumed arriving equilibrium rapidly that might overlook the gradual momentum adjustment and the associated dynamics in the near-field IBL. The distance required by the flows reaching a new equilibrium state after the surface discontinuity in the streamwise direction is non-negligible. It has been defined differently that could vary in a considerable extent. For instance, it changes from $13.1 \delta$ to $98.4 \delta$ based on the definition threshold (1\% to $10 \%$ in velocity-difference; Cheng and Castro, 2002). Besides, it is estimated in the range of $11 \delta$ to $27 \delta$ according to the definitions from velocity-difference and shear stress (Lee and Sung, 2007; Lee 2015).

Log-law, horizontal homogeneity and rapid equilibrium are not compulsory in computational fluid dynamics (CFD) so the flow adjustment can be calculated in detail. CFD has shown a remarkable agreement with the theoretical and experimental results (Onishi and Estoque, 1968; Antonia and Luxton, 1971; Wood, 1982; Cheng and Porté-Agel, 2015). Especially for enhanced CFD based on datadriven techniques and DNS-assistant modelling (Duraisamy, et al. 2019; Tryggvason et al. 2016). For example, the IBL growth calculated by both the Reynolds-averaged Navier-Stokes (RANS) equations (Peterson 1969) and the large-eddy simulation (LES; Lin et al. 1997) follows Eq. (2). In the stationary atmospheric surface layer over homogeneous terrain, the vertical behavior of dimensionless mean flow and turbulence properties could be described as a function of the MoninObukhov key parameters. Whereas, the dimensionless wind shear in neutral conditions

$\Phi=\frac{\kappa(z-d)}{u_{\tau}} \times \frac{\partial \bar{u}}{\partial z}$

does not converge to unity in the near-wall region after surface discontinuity where the MoninObukhov Similarity Theory (MOST) does not work (Rao et al. 1974). Additional CFD therefore commenced to look into the regions after the discontinuity where the dynamics does not yet arrive equilibrium (Deaves 1981; Bergström 1986). The aforementioned CFD studies used only the roughness length $z_{0}$ to model the aerodynamic effect, which, however, merely accounts for the transition dynamics in non-equilibrium flows (Abkar and Porté-Agel 2012). Equation (1) is thus inapplicable.

Unlike analytical solutions and CFD, roughness elements were resolved explicitly in laboratory experiments and field measurements. It was shown that the downward momentum flux $\left(-\overline{u^{\prime \prime} w^{\prime \prime}}\right)$ rises and drops for smooth-to-rough and rough-to-smooth transitions, respectively, in response to the near-wall turbulence kinetic energy (TKE) production/sink 
(Bradley 1968). The changes in surface roughness together with topography elevation could perturbate the vertical flows as high as quarter horizontal wind speeds (Lo and McBean 1977) so deviations from the log-law were commonly found (Sacré 1981). The flows and TKE are not in equilibrium (heterogenous terrain) hence MOST breaks down (Antonia and Luxton 1971). In fact, majority field campaigns have focused on how the changes in ground-level heat flux (instead of surface roughness) influence the IBL (Vickers and Mahrt 1999). Generally, onshore (offshore) winds slow down (speed up) but the turbulence is elevated (suppressed) that builds up an unstable (a stable) IBL subsequently (Smedman et al. 1997). The surface fluxes of heat and momentum in response to the rapid, non-equilibrium processes are also different substantially from those predicted by MOST (Mahrt et al. 1998). Although refined field measurements partly explained the poor correspondence with MOST, their spatial resolution was too coarse for detailed examination of the mechanism (Grachev et al. 2018). CFD has been conducted mainly for a single, idealised hill but not natural, complex topography (Apsley and Castro, 1997; Kim et al. 2000; Prospathopoulos et al. 2012; Chaudhari et al. 2014 and Blocken et al. 2015).

The IBL height $h$ is used to be determined empirically (Raynor et al. 1979) or by the difference in wind speeds (Antonia and Luxton 1971; Cheng and Castro 2002) and stress (Efros and Krogstad 2011). Whereas, the diversified definitions available in literature would lead to a confusing comparison (Savelyev and Taylor, 2005; Floors et al. 2011) and the uncertainty could be up to $50 \%$ (Shir 1972). In this paper, a systematic CFD study is carried out to address the critical research questions listed above. The numerical methods and BCs are detailed in Section 2. The flows over homogeneous wavy surface are characterized in Section 3.1. The impact of an abrupt change in surface roughness on the dynamics is discussed in Section 3.2. Afterwards, the transition over idealised surfaces roughness is extended to natural topography (Hong Kong Island), where the flows encounter sea-to-land transition, in Section 3.3. Conclusions are drawn in Section 4.

\section{Methodology}

\subsection{Mathematical Model}

The Reynolds-averaged Navier-Stokes (RANS) shear-stress transport (SST) $k$ - $\omega$ turbulence model is used in this study. It possesses the favourable performance of both $k-\omega$ and $k-\varepsilon$ turbulence models that is capable of handling adverse pressure gradient as well as flow separation (Menter et al. 1994). The governing equations consist of the mass conservation for incompressible flows

$$
\frac{\partial \bar{u}}{\partial x_{i}}=0
$$

and the steady-state momentum conservation $\bar{u}_{j} \frac{\partial \bar{u}_{i}}{\partial x_{j}}=-\frac{\partial \bar{p}}{\partial x_{i}}+v \frac{\partial^{2} \bar{u}_{i}}{\partial x_{j} \partial x_{j}}+\frac{\partial R_{i j}}{\partial x_{j}}$

with the eddy-viscosity model where

$$
R_{i j}=2 v_{t} S_{i j}-\frac{2}{3} k \delta_{i j}
$$

is the Reynolds stress tensor,

$S_{i j}=\frac{1}{2}\left(\frac{\partial \bar{u}_{i}}{\partial x_{j}}+\frac{\partial \bar{u}_{j}}{\partial x_{i}}\right)$

the strain rate tensor and $\delta_{i j}$ the Kronecker delta. The turbulence is handled by the transport of TKE

$\bar{u}_{j} \frac{\partial k}{\partial x_{j}}=R_{i j} \frac{\partial \bar{u}_{i}}{\partial x_{j}}-\beta^{*} \omega k+\frac{\partial}{\partial x_{j}}\left[\left(v+\sigma_{k} v_{t}\right) \frac{\partial k}{\partial x_{j}}\right]$

and specific dissipation rate $\omega$

$$
\begin{aligned}
& \frac{\partial(\rho \omega)}{\partial t}+u_{j} \frac{\partial(\rho \omega)}{\partial x_{j}}=R_{i j} \frac{\gamma}{v_{t}} \frac{\partial \bar{u}_{i}}{\partial x_{j}}-\beta \rho \omega^{2}+ \\
& \frac{\partial}{\partial x_{j}}\left[\left(\mu+\sigma_{\omega} \mu_{t}\right) \frac{\partial \omega}{\partial x_{j}}\right]+2\left(1-F_{1}\right) \frac{\rho \sigma_{\omega 2}}{\omega} \frac{\partial k}{\partial x_{j}} \frac{\partial \omega}{\partial x_{j}}
\end{aligned}
$$

where

$$
F_{1}=\tanh \left\{\left[\min \left[\max \left(\frac{\sqrt{k}}{\rho^{*} \omega z}, \frac{500 v}{z^{2} \omega}\right), \frac{4 \rho \sigma_{\omega 2} k}{C D_{k \omega} z^{2}}\right]\right]^{4}\right\}
$$

is the blending function that is in the range of 0 (away from the wall) to 1 (near the wall). Here,

$C D_{k \omega}=\max \left(\frac{2 \rho \sigma_{\omega 2}}{\omega} \frac{\partial k}{\partial x_{j}} \frac{\partial \omega}{\partial x_{j}}, 10^{-10}\right)$.

The RANS SST $k$ - $\omega$ turbulence model modifies the turbulent eddy diffusivity

$$
v_{t}=\frac{a_{1} k}{\max \left(a_{1} \omega, \Omega_{i j} F_{2}\right)}
$$

from its $k-\varepsilon$ or $k-\omega$ counterparts where

$$
\Omega_{i j}=\frac{1}{2}\left(\frac{\partial \bar{u}_{i}}{\partial x_{j}}-\frac{\partial \bar{u}_{j}}{\partial x_{i}}\right)
$$

is the mean rotation tensor and

$$
F_{2}=\tanh \left\{\left[\max \left(\frac{2 \sqrt{k}}{\beta^{*} \omega z}, \frac{500 v}{z^{2} \omega}\right)\right]^{2}\right\}
$$

another blending function refining the near-wall turbulent transport. The constants are the weighted average $\theta=\theta_{1} F_{1}+\theta_{2}\left(1-F_{1}\right)$ where $\theta_{1}$ and $\theta_{2}$ are the modelling constants from the $k-\varepsilon$ and $k-\omega$ models, respectively (Table 1).

The calculation is implemented by the open-source CFD code OpenFOAM 4.1 (Weller et al. 1998) using the finite volume method (FVM). The pressureimplicit with splitting of operators (PISO) is used to handle the pressure-velocity coupling in 
Table 1 Constants in the turbulence modelling closure.

\begin{tabular}{|c|c|c|c|c|c|c|c|c|c|}
\hline \multicolumn{4}{|c|}{$k-\varepsilon\left(\theta_{1}\right)$} & \multicolumn{4}{c|}{$k-\omega\left(\theta_{2}\right)$} & \multicolumn{2}{c|}{ SST $k-\omega$} \\
\hline$\sigma_{k 1}$ & $\sigma_{\omega 1}$ & $\beta_{1}$ & $\alpha_{1}$ & $\sigma_{k 2}$ & $\sigma_{\omega 2}$ & $\beta_{2}$ & $\alpha_{2}$ & $\beta^{*}$ & $a_{1}$ \\
\hline 0.85 & 0.5 & 0.075 & 0.5556 & 1.00 & 0.856 & 0.0828 & 0.44 & 0.09 & 0.31 \\
\hline
\end{tabular}

Table 2 Configuration of the CFD domain for the idealised wavy surfaces.

\begin{tabular}{|c|c|c|c|c|c|c|c|}
\hline \multirow[b]{2}{*}{ Usage } & \multirow[b]{2}{*}{ Case } & \multicolumn{3}{|c|}{ Surface parameters } & \multirow{2}{*}{$\begin{array}{c}\text { Domain size } \\
L_{x} \times L_{z}\end{array}$} & \multirow{2}{*}{$\begin{array}{l}\text { Friction } \\
\text { velocity } \\
u_{\tau}(\mathrm{m} / \mathrm{s})\end{array}$} & \multirow{2}{*}{$\begin{array}{c}\text { Reynolds } \\
\text { number } \\
\left(\operatorname{Re}=U_{\infty} \delta / v\right)\end{array}$} \\
\hline & & $\begin{array}{c}\text { Amplitude } \\
(\mathrm{mm})\end{array}$ & Wavelength & $\begin{array}{c}\mathrm{RC}= \\
\ln \left(z_{0,1} / z_{0,2}\right)\end{array}$ & & & \\
\hline \multirow{3}{*}{ Validation } & 0 & $\Lambda=2.54$ & $\lambda=20 \Lambda$ & \multirow{3}{*}{ N.A. } & $2 \lambda \times 20 \Lambda$ & 0.23 & $1.52 \times 10^{5}$ \\
\hline & 1 & $\Lambda=100$ & $\lambda=20 \Lambda$ & & $12 \lambda \times 20 \Lambda$ & 1.41 & $4.8 \times 10^{7}$ \\
\hline & 2 & $\Lambda=100$ & $\lambda=20 \Lambda$ & & $12 \lambda \times 100 \Lambda$ & 3.16 & $2.4 \times 10^{8}$ \\
\hline \multirow{7}{*}{$\begin{array}{c}\text { Homogeneous } \\
\text { Surface }\end{array}$} & 3 & \multirow{7}{*}{$\Lambda=100$} & $\lambda=11 \Lambda$ & \multirow{7}{*}{ N.A. } & \multirow{7}{*}{$12 \lambda \times 100 \Lambda$} & \multirow{7}{*}{3.16} & \multirow{7}{*}{$2.4 \times 10^{8}$} \\
\hline & 4 & & $\lambda=12 \Lambda$ & & & & \\
\hline & 5 & & $\lambda=13 \Lambda$ & & & & \\
\hline & 6 & & $\lambda=14 \Lambda$ & & & & \\
\hline & 7 & & $\lambda=15 \Lambda$ & & & & \\
\hline & 8 & & $\lambda=25 \Lambda$ & & & & \\
\hline & 9 & & $\lambda=30 \Lambda$ & & & & \\
\hline \multirow{3}{*}{$\begin{array}{c}\text { Discontinuous } \\
\text { Surface }\end{array}$} & 10 & \multirow{3}{*}{$\begin{array}{c}\Lambda_{1}=\Lambda_{2}=\Lambda \\
\quad(=100)\end{array}$} & $\begin{array}{l}\lambda_{1}=30 \Lambda \\
\lambda_{2}=20 \Lambda\end{array}$ & -1.08 & $\left(4 \lambda_{1}+12 \lambda_{2}\right) \times 100 \Lambda$ & $\begin{array}{l}3.16 \\
\text { to } 3.60\end{array}$ & \multirow{3}{*}{$2.4 \times 10^{8}$} \\
\hline & 11 & & $\begin{array}{l}\lambda_{1}=30 \Lambda \\
\lambda_{2}=15 \Lambda\end{array}$ & -1.48 & $\left(4 \lambda_{1}+16 \lambda_{2}\right) \times 100 \Lambda$ & $\begin{array}{c}3.16 \\
\text { to } 3.86\end{array}$ & \\
\hline & 12 & & $\begin{array}{l}\lambda_{1}=30 \Lambda \\
\lambda_{2}=10 \Lambda\end{array}$ & -1.59 & $\left(4 \lambda_{1}+24 \lambda_{2}\right) \times 100 \Lambda$ & $\begin{array}{c}3.16 \\
\text { to } 3.92\end{array}$ & \\
\hline
\end{tabular}

incompressible flows. The first-order-accurate, implicit Euler scheme is used in the time integration. The second-order-accurate, bounded Gauss linearupwind and Gauss linear (central difference) schemes are employed in the convection and diffusion terms, respectively. All the prognostic equation systems are solved by the Gauss-Seidel iteration while the pressure Poisson equation is solved by the generalized algebraic multigrid (GAMG). The residual is less than $10^{-12}$.

\subsection{Computational Domain and Boundary Conditions}

\subsubsection{Idealised Wavy Surfaces}

Sinusoidal surfaces are used as the idealised rough solid boundaries at the bottom of the twodimensional (2D) spatial domain. Their elevation is described by $z_{w}=\Lambda \sin (2 \pi x / \lambda)$. The amplitude-towavelength ratio $\Lambda / \lambda$ is adjusted to change the aerodynamic resistance. The number of wave units is $N=L_{x} / \lambda$ for the homogeneous surfaces (Fig. 1a). One of the CFD domains (Case 0; Table 2) replicates the water channel experiment of Hudson et al. (1996). The domain size of other cases is expanded to investigate the IBL development. Cases 0, 1 (larger amplitude $\Lambda$ ) and 2 (larger domain size $L_{x}$ and $L_{z}$ ) are selected to facilitate the model validation. The remaining seven configurations (Cases 3 to 9) are carried out to quantify the aerodynamic resistance. Only smoothto-rough transition (Cases 10 to 12) are considered in which the total number of wave units is $N=$ $L_{x, 1} / \lambda_{1}+L_{x, 2} / \lambda_{2}$. The amplitude $\Lambda$ is kept constant in this paper so only the downstream wavelength $\lambda_{2}$ is altered to modulate the change in surface roughness. For presentation purposes, the upstream and downstream wave units are marked by negative ( -2 and -1 , etc.) and positive $(+1$ and +2 , etc.) indices, respectively (Fig. 1b).

No-slip BCs with wall models are applied on the wavy surfaces. In the homogeneous-surface cases, the flows are driven by a constant, background pressure gradient $\Delta P_{x}$ and periodic $\mathrm{BCs}$ are applied in the streamwise domain. The fully developed inflow generated from homogeneous surface Case 9 $\left(\lambda_{1}=30 \Lambda\right)$ is mapped to the domain inlet of the discontinuous-surface cases to initiate the dynamics. The Neumann BCs are prescribed on the domain top and outlet. The freestream wind speed $U_{\infty}$ and the height of the turbulent boundary layer (TBL) $\delta\left(=L_{z}\right)$ are employed as the characteristic scales of velocity and length, respectively. The viscous length scale $v / u_{\tau}$ is in the range of $2.55 \times 10^{-7}$ to $4.35 \times 10^{-6} \mathrm{~m}$, where $v\left(=10^{-6} \mathrm{~m}^{2} \mathrm{sec}^{-1}\right)$ is the kinematic viscosity. The Reynolds number $R e(=U \infty \delta / v)$ varies from $10^{5}$ to $10^{8}$ (Table 2).

\subsubsection{Natural Topography}

The theory formulated based on the idealised cases is then tested by the natural topography of Hong Kong (HK) Island over which the IBL is initialized by the sea-land transition and the flows are adjusted by the topography elevation. HK Island (Fig. 1c) is situated in the southern area of Hong Kong Special Administrative Region (HKSAR). It has hilly terrain that faces the South China Sea. Its three-dimensional 


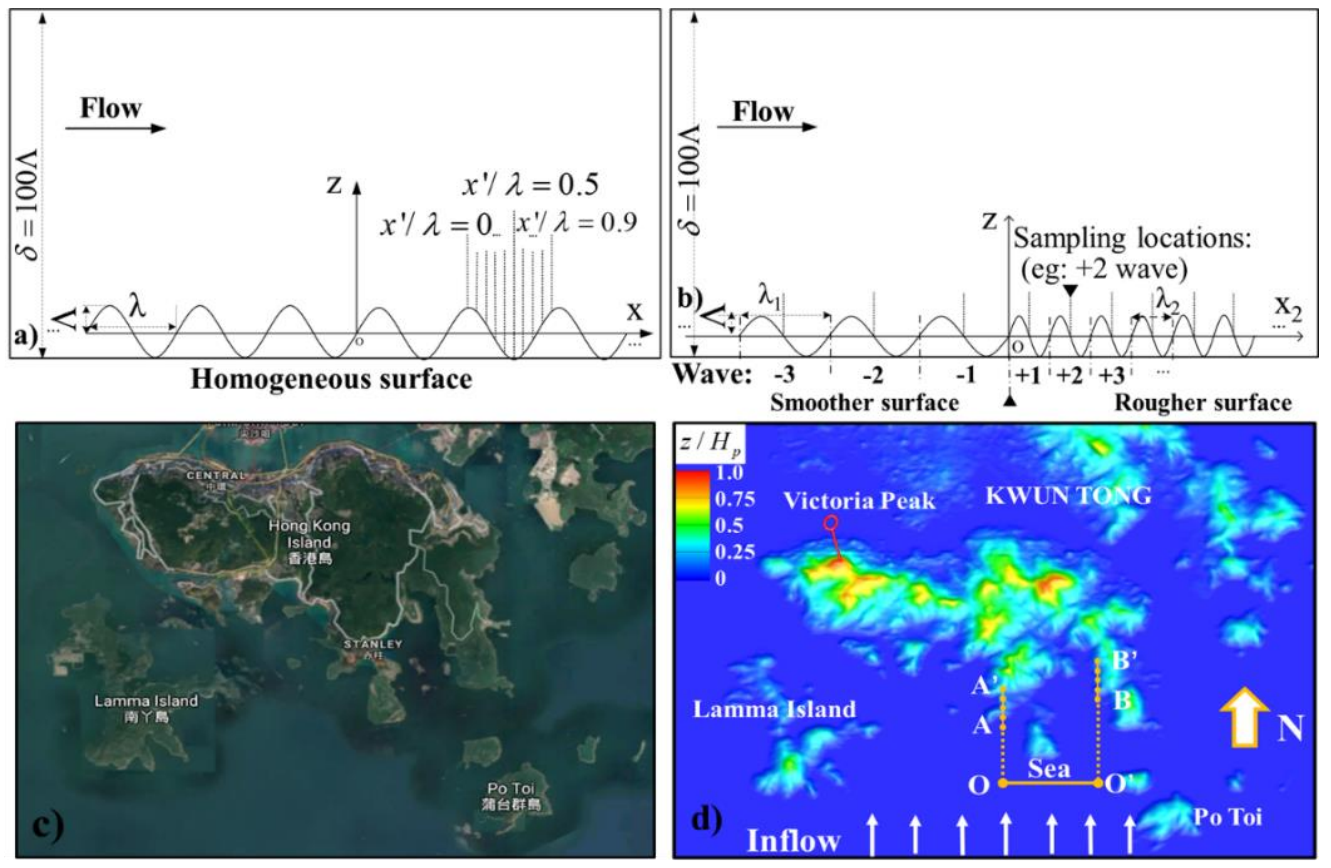

Fig. 1. Computational domains of: (a) homogeneous wavy surface, (b) discontinuous wavy surface; (c) map of Hong Kong Island (d) digital height map of Hong Kong Island in the modeling.

(3D) digital model is built to investigate the flows above offshore islands (Fig. 1d).

The spatial domain sizes $86.3 H_{p}$ (northward) $\times$ $42.2 H_{p}$ (eastward) $\times 16.8 H_{p}$ (height) where $H_{p}(=554$ $\mathrm{m}$ ) is the height of Victoria Peak (the highest point in HK Island). No-slip (wall model) and Neumann BCs are adopted, respectively, on the terrain surfaces and the lateral/vertical boundaries. Alike the above idealised cases, a set of homogeneous-surface calculation (for fully developed flows over the sea) is conducted in-prior to prepare the inlet profiles for the natural topography (Han et al. 2016). The number of FVM cells for the cases of prior computation and natural topography is 1.56 million and 14.16 million, respectively.

\section{Results AND Discussion}

\subsection{Homogeneous Wavy Surfaces}

The current CFD results of homogeneous wavy surfaces (Cases 0 to 2 ) are validated against the water channel experiments of Hudson et al. (1996). The CFD-calculated vertical profiles of dimensionless mean streamwise velocity $\bar{u} / u_{\tau}$ over a unit of wavy surface $\left(0.1 \leq x^{\prime} / \lambda \leq 0.9\right.$; where $x^{\prime}$ is the streamwise distance after the crest) agree well with the measurements (Fig. 2a). A mild under-prediction is observed close to the wavy surface over the trough $\left(x^{\prime}=0.5 \lambda\right)$ that is attributed to the rapid acceleration after the leeward slope together with the recirculating flows within $0.2 \leq x^{\prime} / \lambda \leq 0.6$. It is observed that the location of separation zone in Case 0 compares well with that of the experiments (Fig. 2b). Conventionally, the influence from wavy surfaces on the outer flows $(z>3 \Lambda)$ is negligible (Buckles et al. 1983 ) with which the current CFD agrees.

Comparing the experiments and the current CFD, a noticeable difference in the downward momentum flux $-\overline{u " w "}$ is found in the near-wall region on the windward side $\left(0.5 \leq x^{\prime} / \lambda \leq 0.7\right)$. The discrepancy could be mainly caused by the different Reynolds number, $R e=6,760$ in the experiments and $R e=$ $1.52 \times 10^{5}$ in Case 0 , which would affect the peaked shear stress after the flow reattachment (Michioka, 2018). Moreover, handling flow separation is an implicit weakness of RANS turbulence models whose uncertainty is reported in recent studies (Gorlé et al. 2019; Xiao et al. 2019). The downward momentum flux $\left(-\overline{u " w^{\prime \prime}}=1.5 u_{\tau}^{2}\right)$ is peaked at $z=$ $\Lambda$ over the trough $\left(x^{\prime}=0.5 \lambda\right)$, signifying the major entrainment associated with the recirculating flows. After the reattachment $\left(x^{\prime} / \lambda \geq 0.7\right)$, the CFDcalculated maximum momentum flux descends $(z=$ $0.4 \Lambda)$ that is lower than that of the experiments $(z=$ $1.3 \Lambda$ ). The deviation is caused by the elevated wind shear in the accelerating upslope flows. Whereas, the momentum flux measured in the experiments does not diminish at the wall at $x^{\prime} / \lambda=0.7$ that is likely caused by the instrumentation difficulty close to solid boundaries (Calhoun and Street, 2001). The overall results of Case 0 are closer to those of the experiment. Nonetheless, Cases 0, 1 and 2 agree well as expected because the flows depend mainly on the amplitude-to-wavelength ratio $\Lambda / \lambda$ in a dimensionless manner (De Angelis et al. 1997).

Considering all the geometric details of roughness elements on the dynamics is impractical because of the over-complication. The wall shear stress $\tau_{w}$ over the homogeneous wavy surface is in equilibrium 

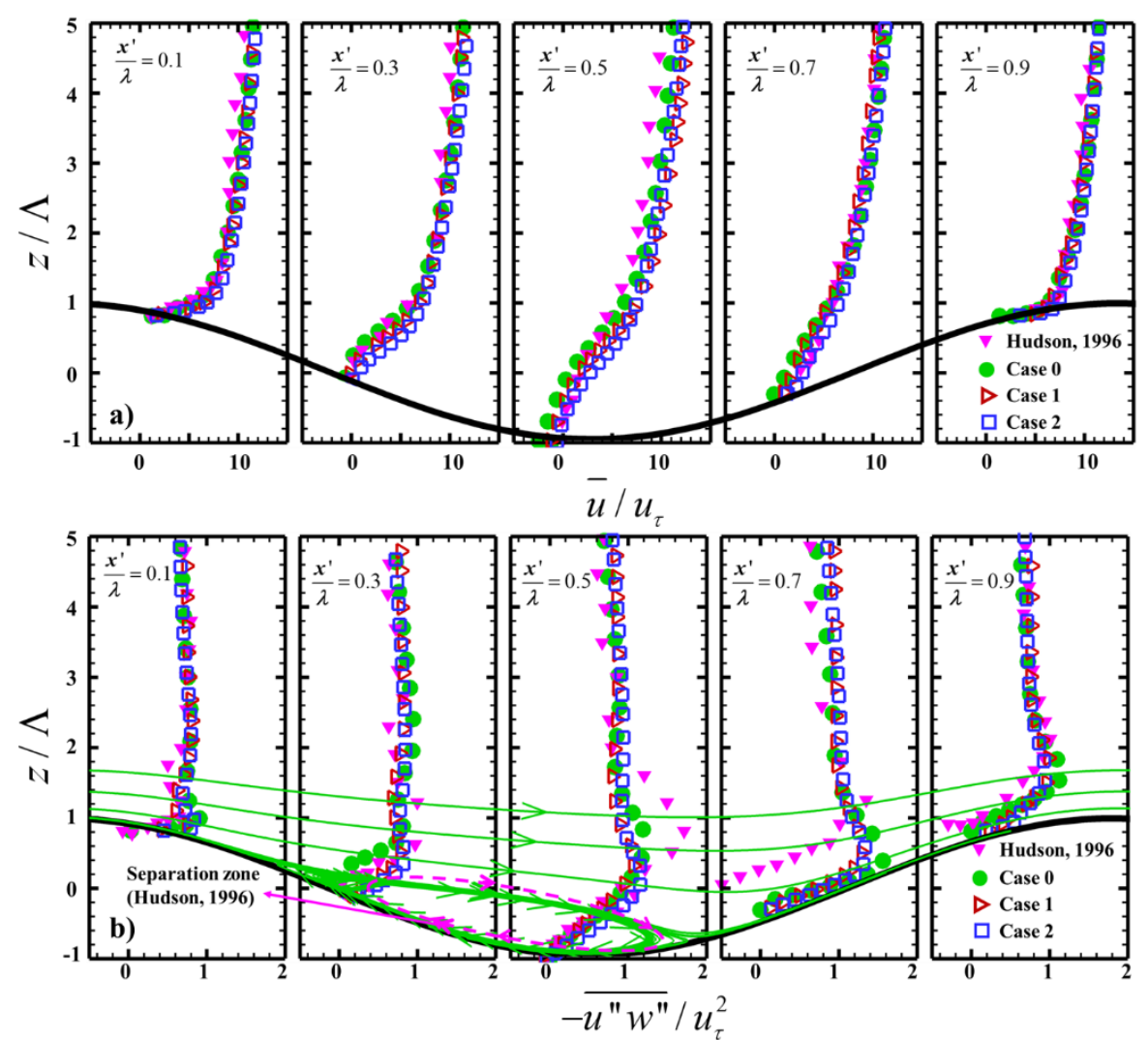

Fig. 2. Vertical profiles of (a) mean streamwise velocity $\bar{u} / u_{\tau}$ and (b) momentum flux $-\overline{u " w "} / u_{\tau}^{2}$ together with the streamlines (Case 0 ) over a unit of idealised wavy surface.
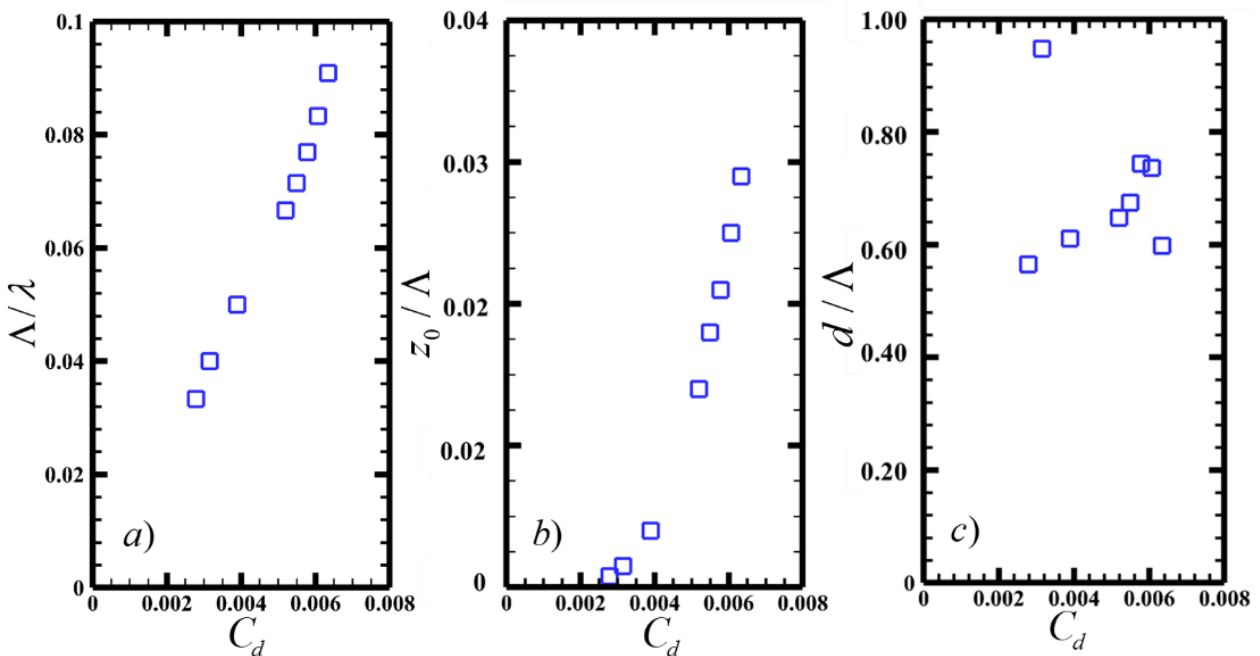

Fig. 3. Ratios of (a) amplitude-to-wavelength $\Lambda / \lambda$; (b) roughness-length-to-amplitude $z_{0} / \Lambda$ and (c) zeroplane-displacement-height-to-amplitude $d / \Lambda$ plotted against drag coefficient $C_{d}$ of homogeneous wavy surfaces.

with the background pressure gradient $\Delta P_{x}$. In this connection, the drag coefficient $C_{d}\left(=2 \tau_{w} / \rho U_{\infty}^{2}\right)$ is an indicator of the aerodynamic resistance. The amplitude-to-wavelength ratio $\Lambda / \lambda$ is proportional to the drag coefficient $C_{d}$ (Fig. 3a) because flows separate earlier over surfaces with greater $\Lambda / \lambda$ (Yoon et al. 2009). Similarly, the roughness length $z_{0}$ increases monotonically with increasing drag coefficient $C_{d}$ (Fig. 3b). Therefore, the amplitudeto-wavelength ratio of the sinusoidal surfaces is controlled to modulate the drag coefficient. Unexpectedly, there is no noticeable relation between the zero-plane displacement height $d$ and the drag coefficient $C_{d}$ (Fig. 3c). It is consistent with 

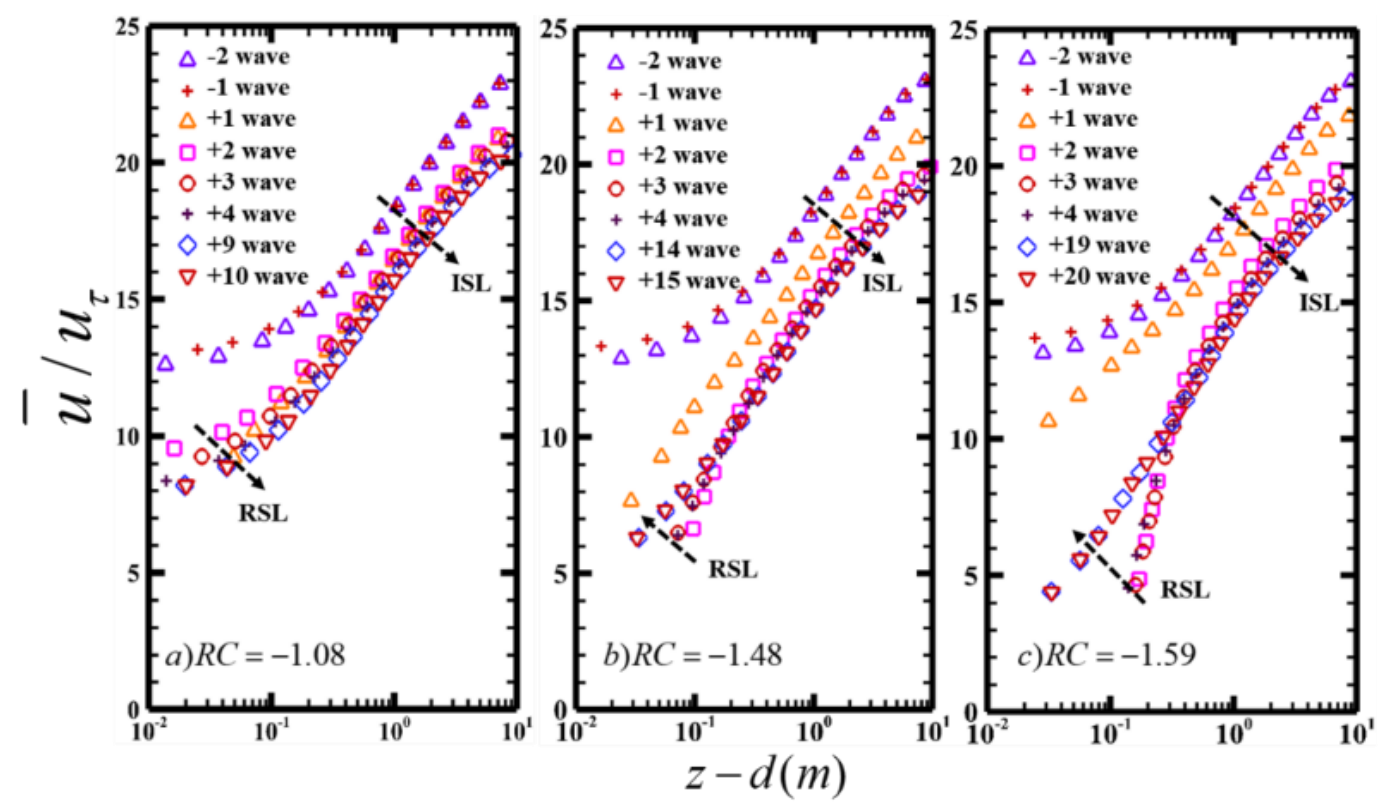

Fig. 4. Vertical profiles of mean streamwise velocity $\bar{u} / u_{\tau}$ over discontinuous wavy surfaces.
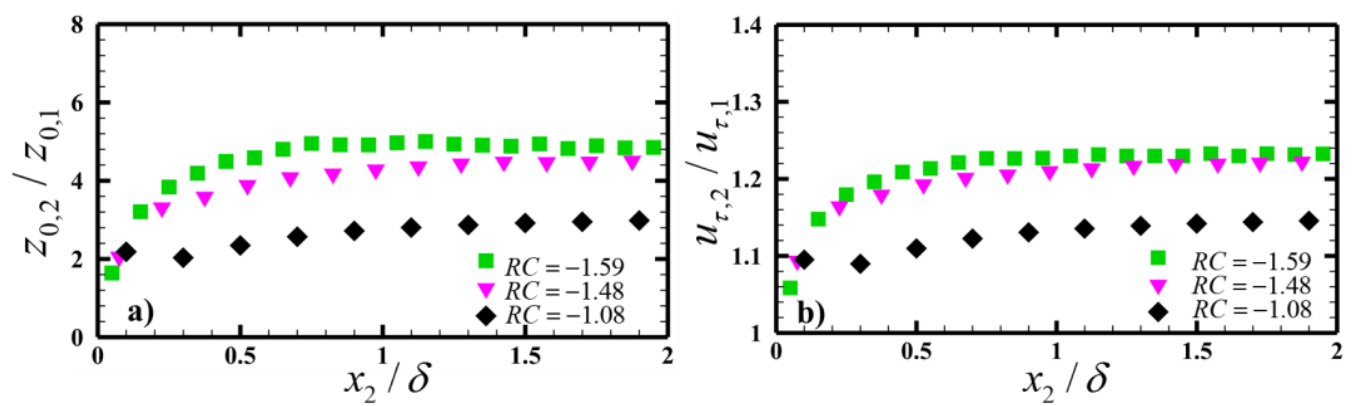

Fig. 5. Growth of (a) roughness-length ratio $z_{0,2} / z_{0,1}$ and (b) friction-velocity ratio $u_{\tau, 2} / u_{\tau, 1}$ after roughness change.

the findings for flows over other types of roughness elements in wind tunnel experiments (Mo and Liu, 2018).

\subsection{Discontinuous Wavy Surfaces}

Three cases of flow over discontinuous wavy surfaces are examined to contrast the dynamics. Their roughness transition is measured by the roughness length ratio $R C=\ln \left(z_{0,1} / z_{0,2}\right)$. Specifically, $z_{0,1}$ and $z_{0,2}$ are the roughness lengths over upstream and far downstream surfaces that are obtained by the linear regression of Eq. (1) in the ISL. This study focuses on the near-field dynamics in the core so only the flows above the crest $(z>\Lambda)$ are concerned.

Although the flows are not yet equilibrium, vertical profiles of mean streamwise velocity (normalized by the local friction velocity) across an abrupt change in surface roughness largely follow the log-law (Fig. 4). The upstream dimensionless wind speeds $\bar{u} / u_{\tau}$ are horizontally homogeneous regardless of the rough surfaces. After the surface discontinuity, the flows decelerate sharply (within one to two wave units) in response to the increasing aerodynamic resistance. It is consistent with the findings in previous studies that the flow adjustment after surface discontinuity could take place fairly rapidly (Antonia and Luxton, 1971; Cheng and Castro, 2002). The downward-shifting wind-speed profiles signify the flow deceleration. They deepen with increasing roughness change when the flows are adjusting to the new (rougher) surface in the streamwise direction. Moreover, the streamwise distance required to resume to horizontal homogeneity increases with increasing roughness length change.

Different from previous studies, the roughness elements are explicitly resolved by CFD in this study so the RSLs are clearly depicted (Fig. 4). RSLs are initiated by individual roughness elements. The highly inhomogeneous flows subsequently promote mixing which is signified by the more uniform wind profiles. In this study, the RSL develops gradually whose evolution over the surface discontinuities is depicted. For the least roughness change $R C=-1.08$, the RSL thinners slightly (from $z-d=0.2$ to 0.1 ) that adjusts quickly 
to the rougher surface. The RSL with rather uniform winds persists. Increasing the roughness length ratio to $R C=-1.48$, the RSL turns subtle whose difference from ISL is mild. The RSL wind shear increases after the discontinuity that attains its maximum after 2 wave units and finally converges. In the maximum roughness change $R C$ $=-1.59$, the wind shear increases sharply and the ISL bottom is elevated $(z-d \sim 0.5)$. The flows then adjust gradually to the rougher surface but the RSL is no longer noticeable. Nonetheless, the near-wall flows after surface discontinuity deviate from the log-law so solving the RSLs explicitly is necessary.

Both roughness length $z_{0}$ and friction velocity $u_{\tau}$ grow over the downstream (rougher) surfaces (Fig. 5 ). The ratios $z_{0,2} / z_{0,1}$ and $u_{\tau, 2} / u_{\tau, 1}$ increase sharply after the surface discontinuity that converge far downstream. The change in $z_{0,2} / z_{0,1}(1.64$ to 4.99$)$ is greater than that in $u_{\tau, 2} / u_{\tau, 1}$ (1.06 to 1.23$)$. Further to Eq. (3), it is derived that

$u_{\tau, 2} / u_{\tau, 1}=\left(z_{0,2} / z_{0,1}\right)^{n}$.

The exponent $n$ (Fig. 6) shows a rather constant value throughout the streamwise extent regardless of the large changes in roughness-length ratio $(R C=-3.4$ to $R C=-1.08)$. It is revealed that the exponent $n$ is almost a constant between 0.12 and 0.16 . This range of value agrees well with that of previous studies (Taylor 1962; Cheng and Castro, 2002).

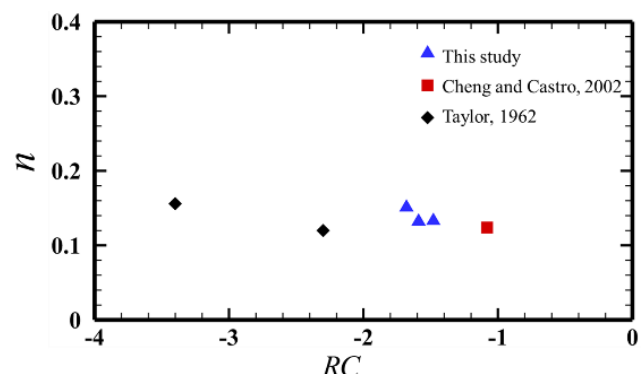

Fig. 6. Exponent $\boldsymbol{n}$ [Eq. (16)] plotted against roughness length ratio $R C$.

The aforementioned flow structure can alternatively be explained by the evolution of the downward momentum flux $-\overline{u " w^{\prime \prime}}$ (Fig. 7). The momentum flux takes a longer distance to adjust itself than does the mean streamwise velocity $\bar{u}$. It entrains to the IBL to overcome the increased aerodynamic resistance over a rougher surface. Under this circumstance, the near-wall $(z \leq 0.03 \delta)$ downward momentum flux increases that drags the outer flows and lowers the downward momentum aloft. This variation of momentum flux takes place below the ISL $(z \leq 0.1 \delta)$, demonstrating the importance of resolving RSL dynamics. The mechanism is elaborated in the upcoming sections.

The current CFD-calculated stress-change $\left(\tau_{2}\right.$ $\left.\tau_{1}\right) /\left(\tau_{w, 2}-\tau_{1}\right)$ and dimensionless wind shear $\Phi$ [Eq.
(4)] in the far field are comparable with those of previous studies (Peterson, 1969; Rao et al. 1974). Here, $h_{0}$ is the height above which the downstream stress $\tau_{2}$ is equal to the upstream one $\tau_{1}$. The dimensionless stress-change obtained from different roughness length ratios exhibits a favourable agreement (Fig. 8). The previous studies employed the log-law BCs so the RSL was not resolved for $(z-$ $\left.z_{0,2}\right) /\left(h_{0}-z_{0,2}\right)<0$. The change of stress diminishes near the solid boundaries due to the existence of roughness elements. In response to the smooth-torough transitions, the dimensionless wind shear $\Phi$ is over unity for $\left(z-z_{0,2}\right) /\left(h_{0}-z_{0,2}\right)>0$. Its maximum $\Phi_{\max }$ is influenced by the roughness length ratio $R C$ together with the streamwise distance $x_{2}$. It is noted that $\Phi_{\max }(=1.8)$ is found in the case $R C=-3.00$ (maximum change in surface roughness). The dimensionless maximum wind shear in the cases $R C$ $=-1.48\left(\Phi_{\max }=1.2\right)$ and $R C=-1.08\left(\Phi_{\max }=1.2\right)$ is smaller than that in $R C=-1.00\left(\Phi_{\max }=1.4\right)$ because their sampling points are farther from the surface discontinuity. Furthermore, $\Phi$ deviates from unity again near the wall $\left(\left(z-z_{0,2}\right) /\left(h_{0}-z_{0,2}\right)<0\right)$ because of the RSL.

After the surface discontinuity, the flow characteristics originated upstream do not vanish immediately. Meanwhile the new surface keeps exerting influence on the flows, resulting in the growth of IBL and ISL. Concurring to Cheng and Castro (2002), we attempt to distinguish the effect of roughness change on the flow structure by locating the IBL and flow structure towards selfsimilarity.

In this study, the IBL is found by subtracting the upstream velocity profile from local velocity profile (Tomas et al. 2017), above which the vertical gradient of velocity difference $\left(\Delta \bar{u}=\bar{u}-\overline{u_{1}}\right)$ reaches zero, and the threshold $|d \Delta \bar{u} / d z|<5 \%$ is used to determine this height. Besides, the ISL thickness is quantified by the dimensionless velocity gradient $\Phi$, whose difference compared with the theoretical value (unity) is less than 5\%, and the RSL is below the ISL obtained.

Developments of IBL and ISL are clearly observed after an abrupt change in surface roughness (Fig. 9). The IBL height rises in response to the ISL adjustment. The ISL flows slow down sharply (within $0.5 \delta$ ) whose development finishes soon after the surface discontinuity. This finding agrees with the rapid changes in both the mean streamwise velocity and the momentum flux obtained above. Therefore, the flows adjust quickly after a surface discontinuity, supporting the crucial assumption commonly employed in the analytical solutions.

While the IBL height is almost the same over the three discontinuous surfaces, it is found that the ISL shrinks faster with increasing the change in surface roughness. The shallower ISL can be explained by the thickening RSL beneath in response to the increasing aerodynamic resistance that is in line with our previous experimental results (Ho and Liu 2016). 


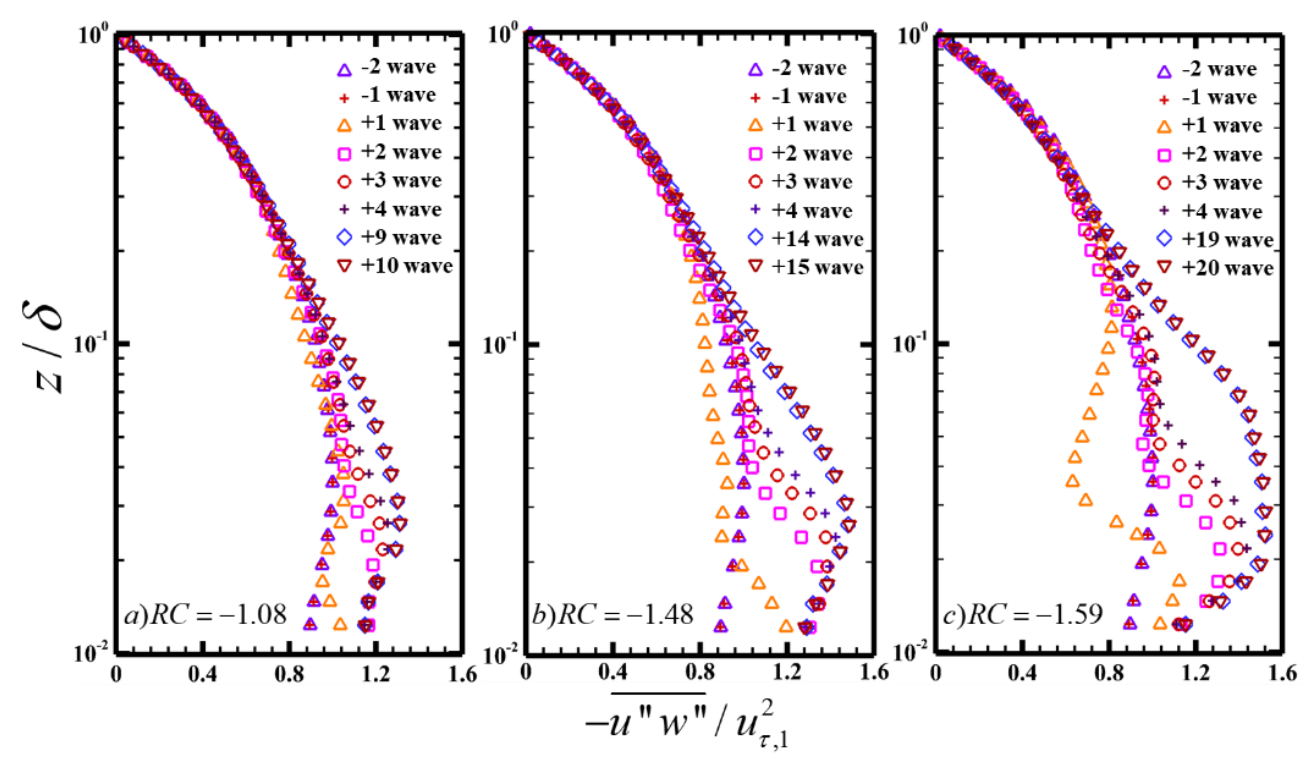

Fig. 7. Vertical profiles of downward momentum flux $-\overline{u " w "}$ over discontinuous wavy surfaces.

\subsection{Natural Topography}

Unlike idealised rough surfaces, natural topography is heterogeneous whose roughness and elevation change continuously. Further to the theory formulated above using sinusoidal wavy surfaces, we attempt to test whether the flowstructure model is applicable to more complicated scenarios via the sea breeze over natural topography. The onshore winds above the (upstream) sea are fully developed and horizontally homogeneous. The effect of (downstream) land surface on the flows diffuses upwards through turbulent transport. Subsequently, the flow features originated from the onshore winds are being dissipated gradually over the land surface in the streamwise direction. The flows on the two selected transversal planes (Fig. 1d) are depicted to contrast the response of onshore winds to sea-land interface. Specifically, plane A-A' is across sea-mountain transition while plane B-B' is near the harbour. Their length is $L=$ $0.18 \delta$. The mean surface elevations are $0.041 H_{p}$ (over plane A-A') and $0.0302 H_{p}$ (over plane BB'). Besides, the standard deviations of surface elevation are $\sigma_{z_{\mathrm{AA}^{\prime}}}=0.033 H_{p}$ and $\sigma_{z_{\mathrm{BB}^{\prime}}}=$ $0.028 H_{p}$, respectively. Vertical profiles of dimensionless streamwise velocity $\bar{u} / u_{\tau}$ at the five selected positions are examined (Fig. 10). The profiles over the sea (plane O-O') are shown for reference. The ISLs and RSLs can be distinguished from the velocity profiles after the coastal line. The ISLs over the sea and land surfaces exhibit various extents of dissimilarity in view of the different changes in surface roughness $\left(R C_{\max }=-5.20\right.$ on plane $\mathrm{A}-\mathrm{A}^{\prime}$ while $R C_{\max }=-0.65$ on plane B-B').

To illustrate the atmosphere-terrain interaction across different sea-land interfaces, the speed-up ratio

$\Delta S=\frac{\bar{U}(z)-\bar{U} \operatorname{sea}(z)}{\bar{U} \operatorname{sea}(z)}$

and the TKE increase ratio (Conan, et al. 2016)

$\Delta K=\frac{\operatorname{TKE}(z)-\operatorname{TKEsea}(z)}{\operatorname{TKEsea}(z)}$

on the two planes are compared at $z=0.01 \delta$ and $0.05 \delta$ (Fig. 11). After the surface discontinuity, the near-ground flows $(z=0.01 \delta)$ on plane A-A' decelerates $\left(\Delta S_{\min }=-0.3\right)$ that ends up with elevating TKE increase ratio $\left(\Delta K_{\max }=1.08\right)$. On the other hand, the changes on plane B-B' are relatively smaller corresponding to mild roughness transition. At $z=0.05 \delta, \Delta S$ and $\Delta K$ are negligible because of the weaker atmosphere-terrain interaction. In addition, local acceleration is observed (e.g. $0.6 \leq x_{2} / L \leq 0.7$ on plane A-A' and $0.77 \leq x_{2} / L \leq 0.87$ on plane B-B').

The aforementioned flow structure is reasonably applicable to the onshore-wind structure over the sea-land interface of natural topography (Fig. 12). In view of the complex terrain, the flow-structure development is less stable than that of the idealised one. It is also revealed that the growths of IBL and ISL are tied to the changes in surface roughness. The ISL shrink is clearly observed on plane A-A' because the flows encounter a major roughness transition. However, overlapping between IBL and ISL is noted on plane $\mathrm{B}-\mathrm{B}$ ' in response to the smaller change in surface roughness.

\section{Conclusions}

A mathematical modelling study is conducted systematically to elucidate the response of flows and 


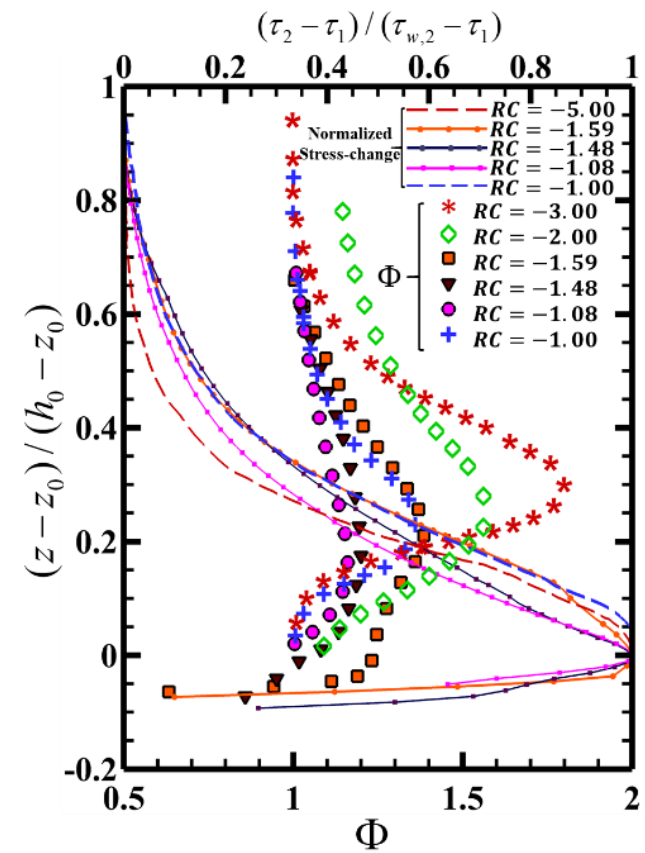

Fig. 8. Dimensionless wind shear $\Phi$ (bottom border) and change in downward momentum flux $\left(\tau_{2}-\tau_{1}\right) /\left(\tau_{w, 2}-\tau_{1}\right)$ (top border) expressed as functions of dimensionless height $\left(z-z_{0}\right) /\left(h_{0}-z_{0}\right)$. Profiles of $\mathrm{RC}=-\mathbf{1}, \mathbf{- 3}$ and -5 (Peterson,1969) are located at $x_{2} / z_{0,2}=10^{2}$, profile of $\mathrm{RC}=-2($ Rao $e t$ al. 1974) is located at $x_{2} / z_{0,2}=8 \times 10^{2}$, profiles of

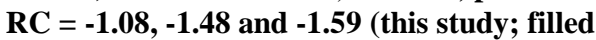
symbols) are located at $x_{2} / z_{0,2} \approx 10^{4}$.
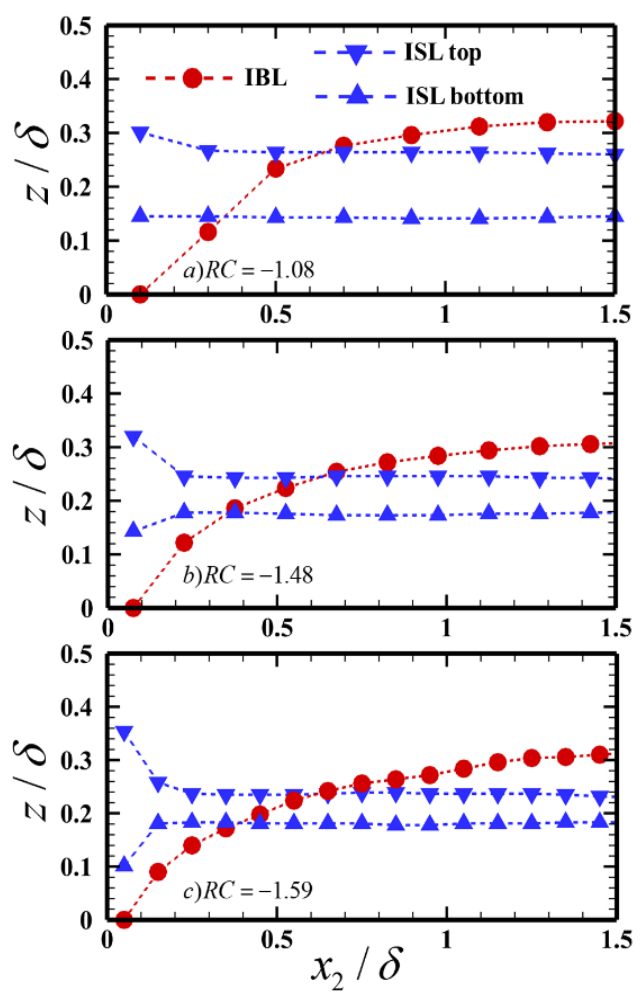

Fig. 9. Development of IBL and ISL after an abrupt change in surface roughness at $x_{2}=0$.
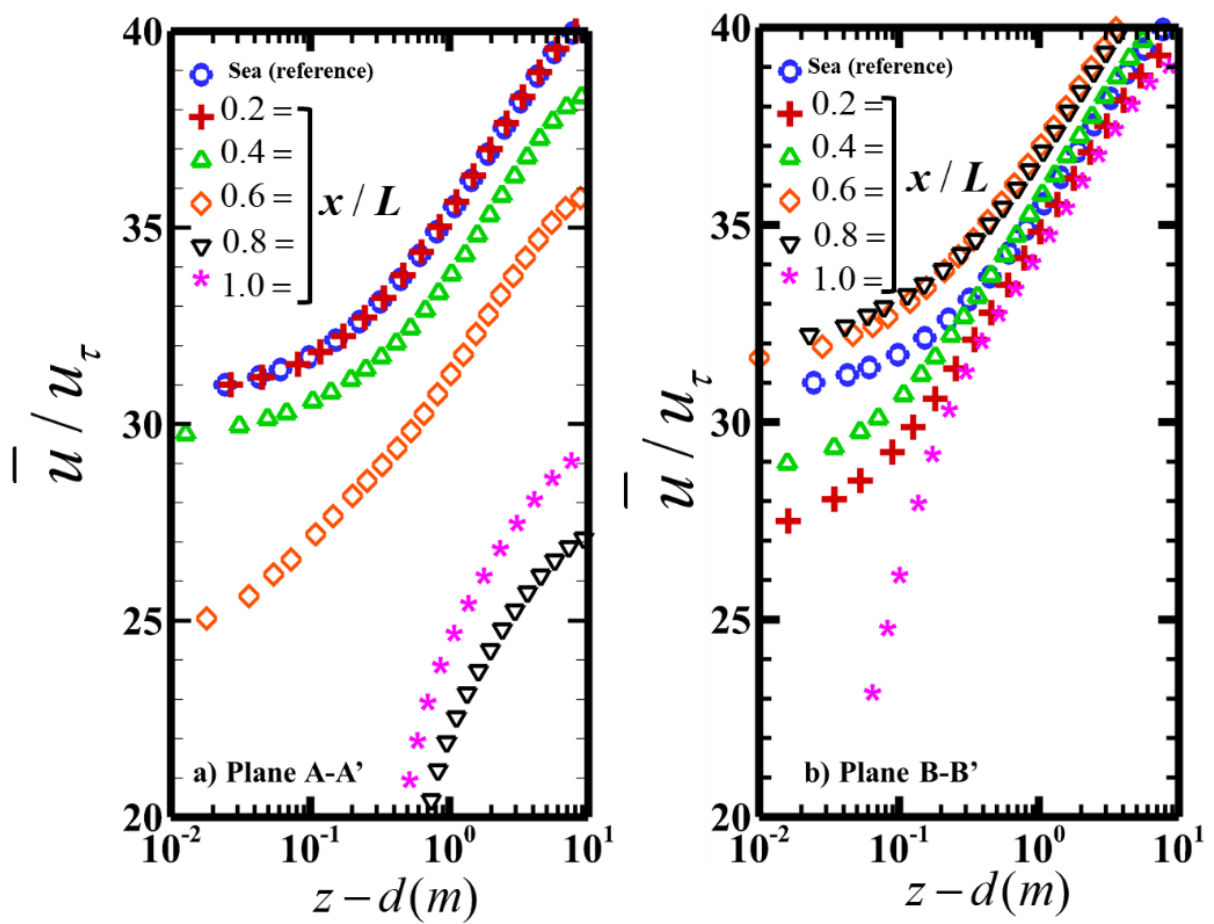

Fig. 10. Vertical profiles of mean streamwise velocity on planes (a) A-A' and (b) B-B' over natural topography (Hong Kong Island). 

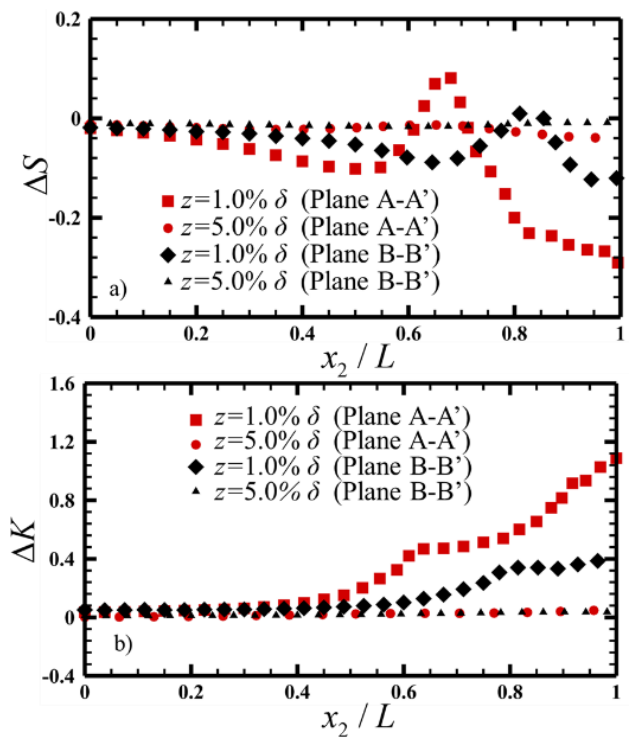

Fig. 11. (a) Speed-up ratio $\Delta S$ and (b) TKE increase ratio $\Delta K$ at $z=0.01 \delta$ and $0.05 \delta$ on planes A-A' and B-B'.

turbulence to an abrupt change in surface roughness. Instead of modelling the aerodynamic resistance by the conventional parameters such as zero-plane displacement height $d$ and roughness length $z_{0}$, idealised (sinusoidal) wavy surfaces are used to construct homogeneous and heterogeneous rough surfaces. The flows around roughness elements are thus explicitly resolved. We purposely resolve the $\mathrm{RSL}$, hence, it is unnecessary to assume ISL/log-law in the near-wall region. This model configuration facilitates the examination of the dynamics before the flows adjust to fully developed over the downstream rougher surface.

After the favourable model validation based on a homogeneous wavy surface, the CFD study is extended to the flow adjustment after a surface discontinuity to elucidate the mechanism. Three levels of abrupt change in surface roughness $(R C=$ $1.08,-1.48$ and -1.59 ) are constructed by wavy surfaces in the parametric tests. It is found that the mean-wind speed $\bar{u}$ and (downward) momentum flux $-\overline{u " w^{\prime \prime}}$ evolve in the streamwise direction, approaching self-similar, fully developed flows over the rougher surfaces. The momentum flux takes a longer distance to adjust itself than does the meanwind speed. Apart from the ISLs, the development of RSLs is observed. Unlike the conventional ISL BCs, the RSLs substantially modify the near-wall dimensionless wind shear $\Phi$ (no longer equal to unity) that violates the MOST. When air flows to a rougher surface, the downward momentum flux increases to overcome the increased aerodynamic resistance. Remarkably, it is verified that the change in friction velocity is closely related to the change in roughness length [Eq. (16)] in which the exponent $n$ is almost a constant.

The developments of IBL and ISL are distinguished

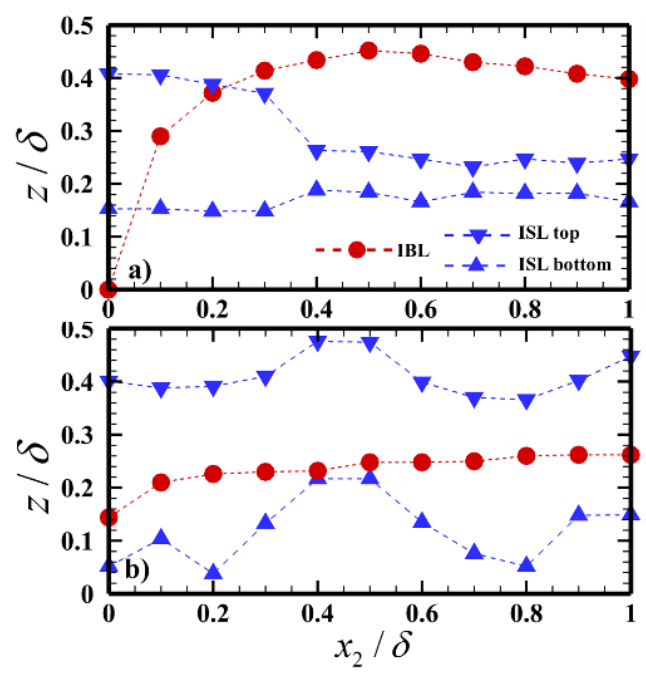

Fig. 12. Development of IBL and ISL on the transversal planes (a) A-A' and (b) B-B' over natural topography (Hong Kong Island).

to collectively demonstrate the influence of surface discontinuity. The increase of IBL height signifies that the effect from the upstream (smoother) surface is being weakened gradually. Simultaneously, ISL adapts to downstream surface rapidly, and the adjustment of flows structure depends on the roughness transition level $z_{0,2} / z_{0,1}$.

The flow characteristics across roughness change are also examined via the atmospheric flows over HK Island (sea-to-land surface transition). Although the flows encounter continuous, complicated changes in both surface roughness and topography elevation, the flows and structure over natural topography are consistent with the findings from idealised surface transitions. In view of the existence of the IBL, the transport processes could be affected after surface discontinuity, quantitative analyses of the transport near/after surface discontinuity will be performed in the future.

\section{ACKNOWLEDGMENT}

This research is conducted in part using the research computing facilities and/or advisory services offered by Information Technology Services (ITS), The University of Hong Kong (HKU). Technical support from Ms. Lilian Y. L. Chan, Mr. W. K. Kwan and Mr. Bill H. T. Yau is appreciated. This work was supported by the General Research Fund (GRF) 17250616 of Hong Kong (HK) Research Grants Council (RGC).

\section{REFERENCES}

Abkar, M. and F. Porté-Agel (2012). A new boundary condition for large-eddy simulation of boundary-layer flow over surface roughness transitions. J. Turbul., 13, N23. 
Antonia, R. A. and R. E. Luxton (1971). The response of a turbulent boundary layer to a step change in surface roughness Part 1. Smooth to rough. Journal of Fluid Mechanics 48 (4), 721761.

Apsley, D. D. and I. P. Castro (1997). A limitedlength-scale $k-\varepsilon$ model for the neutral and stably-stratified atmospheric boundary layer. Boundary-Layer Meteorol. 83(1), 75-98.

Bergström, H. (1986). A simplified boundary layer wind model for practical application. Journal of Applied Meteorology 25, 813-824.

Blocken, B., A. van der Hout, J. Dekker and O. Weiler(2015). CFD simulation of wind flow over natural complex terrain: case study with validation by field measurements for Ria de Ferrol, Galicia, Spain. Journal of Wind Engineering and Industrial Aerodynamics 147, 43-57.

Bradley, E. F. (1968). A micrometeorological study of velocity profiles and surface drag in the region modified by a change in surface roughness. Quarterly Journal of the Royal Meteorological Society 94(401), 361-379.

Buckles, J. J. (1983). Turbulent separated flow over wavy surfaces, Doctoral dissertation, University of Illinois at Urbana-Champaign.

Calhoun, R. J. and R. L. Street (2001). Turbulent flow over a wavy surface: Neutral case. Journal of Geophysical Research: Oceans 106(C5), 9277-9293.

Chaudhari, A. (2014). Large-eddy simulation of wind flows over complex terrains for wind energy applications. Acta Universitatis Lappeenrantaensis.

Cheng, H. and I. P. Castro (2002). Near-wall flow development after a step change in surface roughness. Boundary-Layer Meteorol. 105(3), 411-432.

Cheng, W. C. and F. Porté-Agel (2015). Adjustment of turbulent boundary-layer flow to idealized urban surfaces: a large-eddy simulation study. Boundary-Layer Meteorology 155, 249-270.

Conan, B., Chaudhari, A., Aubrun, S., van Beeck, J., Hämäläinen, J. and Hellsten, A. (2016). Experimental and numerical modelling of flow over complex terrain: the Bolund hill. Boundary-layer Meteorology 158(2), 183208.

De Angelis, V., P. Lombardi and S. Banerjee (1997). Direct numerical simulation of turbulent flow over a wavy wall. Physics of Fluids, 9(8), 24292442.

Deaves, D. M. (1981). Computations of wind flow over changes in surface roughness. Journal of Wind Engineering and Industrial Aerodynamics 7(1), 65-94

Dellwik, E. and N. O. Jensen (2005). Flux-profile relationships over a fetch limited beech forest. Boundary-Layer Meteorology 115, 179-204.

Duraisamy, K., G. Iaccarino and H. Xiao (2019). Turbulence modeling in the age of data. Annual Review of Fluid Mechanics 51, 357-377.

Efros, V. and P. A. Krogstad (2011). Development of a turbulent boundary layer after a step from smooth to rough surface. Experiments in Fluids 51(6), 1563-1575.

Elliott, W. P. (1958). The growth of the atmospheric internal boundary layer. EOS, Transactions American Geophysical Union 39(6), 10481054

Floors, R., S. E. Gryning, A. Peña and E. Batchvarova (2011). Analysis of diabatic flow modification in the internal boundary layer. Meteorologische Zeitschrift 20(6), 649-659.

Garratt, J. R. (1994). The Atmospheric Boundary Layer, Cambridge University Press, 3rd Edition.

Gorlé, C., S. Zeoli, M. Emory, J. Larsson and G. Iaccarino (2019). Epistemic uncertainty quantification for Reynolds-averaged NavierStokes modeling of separated flows over streamlined surfaces. Physics of Fluids, 31(3), 035101 .

Grachev, A. A., L. S. Leo, H. J. S. Fernando, C. W. Fairall, E. Creegan, B. W. Blomquist. A. J. Christman and C. M. Hocut (2018). Airsea/land interaction in the coastal zone Boundary-Layer Meteorology 167, 181-210.

Han, Y., M. Stoellinger and J. Naughton (2016). Large eddy simulation for atmospheric boundary layer flow over flat and complex terrains. Journal of Physics: Conference Series 753(3), 032044, IOP Publishing.

Ho, Y. K. and C. H. Liu (2017). A wind tunnel study of flows over idealised urban surfaces with roughness sublayer corrections. Theoretical and Applied Climatology 130(1-2), 305-320.

Hudson, J. D., L. Dykhno and T. J. Hanratty (1996). Turbulence production in flow over a wavy wall. Experiments in Fluids 20(4), 257-265.

Kim, H. G., V. C. Patel and C. M. Lee (2000). Numerical simulation of wind flow over hilly terrain. Journal of Wind Engineering and Industrial Aerodynamics 87(1), 45-60.

Lee, J. H. (2015). Turbulent boundary layer flow with a step change from smooth to rough surface. International Journal of Heat and Fluid Flow, 54, 39-54.

Lee, S. H. and H. J. Sung (2007). Direct numerical simulation of the turbulent boundary layer over a rod-roughened wall. Journal of Fluid Mechanics 584, 125-146.

Lin, C. L., C. H. Moeng, P. P. Sullivan and J. C. McWilliams (1997). The effect of surface 
roughness on flow structures in a neutrally stratified planetary boundary layer flow. Physics of Fluids 9, 3235-3249.

Lo, A. K. and G. A. McBean (1977). Boundary layer flow over gentle curvilinear topography with a sudden change in surface roughness. Quarterly Journal of the Royal Meteorological Society 103 (435), 199-209.

Mahrt, L, D. Vickers, J. Edson, J. Sun, J. Højstrup, J. Hare and J. M. Wilczak (1998). Heat flux in the coastal zone. Boundary-Layer Meteorology 86(3), 421-446.

Menter, F. R. (1994). Two-equation eddy-viscosity turbulence models for engineering applications. AIAA Journal 32(8), 1598-1605.

Michioka, T. (2018). Large-eddy simulation for turbulent flow and gas dispersion over wavy walls. International Journal of Heat and Mass Transfer, 125, 569-579.

Mo, Z. and C. H. Liu (2018). A wind tunnel study of ventilation mechanism over hypothetical urban roughness: The role of intermittent motion scales. Building and Environment, 135, 94-103.

Onishi, G. and M. A. Estoque (1968). Numerical study on atmospheric boundary layer flow over inhomogeneous terrain. Journal of the Meteorological Society of Japan 46 (4), 280286.

Panofsky, H. A. and A. A. Townsend (1964). "Change of terrain roughness and the wind profile", Quarterly Journal of the Royal Meteorological Society 90(384), 147-155.

Peterson, E. W. (1971). Predictions of the momentum exchange coefficient for flow over heterogeneous terrain. Journal of Applied Meteorology 10, 958-961.

Peterson, E. W. (1969), Modification of mean flow and turbulent energy by a change in surface roughness under conditions of neutral stability. Quarterly Journal of the Royal Meteorological Society 95, 561-575.

Prospathopoulos, J. M., E. S. Politis and P. K. Chaviaropoulos (2012). Application of a 3D RANS solver on the complex hill of Bolund and assessment of the wind flow predictions. Journal of Wind Engineering and Industrial Aerodynamics 107, 149-159.

Rao, K. S., J. C. Wyngaard and O. R. Coté (1974). The structure of the two-dimensional internal boundary layer over a sudden change of surface roughness. Journal of the Atmospheric Sciences 31(3), 738-746.

Raynor, G. S., S. Sethuraman and R. M. Brown (1979). Formation and characteristics of coastal internal boundary layers during onshore flows. Boundary-Layer Meteorology 16 (3), 487-514.

Sacré, C. (1981), Strong wind structure near a sealand roughness discontinuity. Boundary-Layer
Meteorology 21 (1), 57-76.

Savelyev, S. A. and P. A. Taylor (2005). Internal boundary layers: I. Height formulae for neutral and diabatic flows. Boundary-Layer Meteorology 115(1), 1-25.

Schwiesow, R. L. and R. S. Lawrence (1982). Effects of a change of terrain height and roughness on a wind profile. Boundary-Layer Meteorology 22 (1), 109-122.

Shir, C. C. (1972). A numerical computation of air flow over a sudden change of surface roughness. Journal of the Atmospheric Sciences 29(2), 304-310.

Smedman, A. S., H. Bergström and B. Grisogono (1997). Evolution of stable internal boundary layers over a cold sea. Journal of Geophysical Research: Oceans 102 (C1), 1091-1099.

Taylor, R. J. (1962). Small-scale advection and the neutral wind profile. Journal of Fluid Mechanics 13 (4), 529-539.

Tomas, J. M., H. E. Eisma, M. J. B. M. Pourquie, G. E. Elsinga, H. J. J. Jonker and J. Westerweel (2017). Pollutant dispersion in boundary layers exposed to rural-to-urban transitions: Varying the spanwise length scale of the roughness. Boundary-Layer Meteorology 163(2), 225-251.

Townsend, A. A. (1966). The flow in a turbulent boundary layer after a change in surface roughness. Journal of Fluid Mechanics 26 (2), 255-266.

Tryggvason, G., M. Ma and J. Lu (2016). DNSassisted modeling of bubbly flows in vertical channels. Nuclear Science and Engineering 184(3), 312-320.

Vickers, D and L. Mahrt (1999). Observations of non-dimensional wind shear in the coastal zone. Quarterly Journal of the Royal Meteorological Society 125, 2685-2702.

Weller, H. G., G. Tabor, H. Jasak and C. Fureby (1998). A tensorial approach to computational continuum mechanics using object-oriented techniques. Journal of Computational Physics12(6), 620-631.

Wood, D. H. (1982). Internal boundary layer growth following a step change in surface roughness . Boundary-Layer Meteorology, 22(2), 241-244.

Xiao, H. and P. Cinnella (2019). Quantification of model uncertainty in RANS simulations: A review. Progress in Aerospace Sciences.

Yoon, H. S., O. A. El-Samni, A. T. Huynh, H. H. Chun, H. J. Kim, A. H. Pham and I. R. Park (2009). Effect of wave amplitude on turbulent flow in a wavy channel by direct numerical simulation. Ocean Engineering 36(9-10), 697707. 